\title{
Idiopatiske inflammatoriske myopatier (IIM)
}

\author{
Helena Andersson \\ Revmatologisk avdeling, Rikshospitalet
}

\begin{abstract}
SAMMENDRAG
Inflammatoriske muskelsykdommer er en heterogen gruppe av sykdommer der man i dag inkluderer polymyositt (PM), dermatomyositt (DM) og inklusjonslegememyositt (IBM). IBM er den hyppigste forekommende hos personer > 50 år med en prevalens på 39,5/million i denne aldersgruppen. Insidens av PM/DM er beregnet til 2-10/million med en prevalens på 11/100.000. Spesielt PM og DM kan ha andre organmanifestasjoner der eksempelvis interstitiell lungesykdom kan gi alvorlig sykdom med økt morbiditet og mortalitet. Økt cancer-risiko er påvist spesielt hos DM, evt PM men ikke hos IBM. I den senere tid har man identifisert nye kliniske fenotyper av PM og DM, spesielt gjennom myosittspesifikke antistoff. Noen av disse kan brukes som markører for prognose og sykdomsaktivitet. Det er ønskelig med enhetlig internasjonal klassifikasjon som også omfatter myosittspesifikke antistoff til å utføre nye epidemiologiske/kliniske studier og dermed øke kunnskapen om disse sykdommene.
\end{abstract}

Andersson H. Epidemiology of idiopathic inflammatory myopathies. Nor J Epidemiol 2008; 18 (1): 73-77.

\section{ENGLISH SUMMARY}

Idiopathic inflammatory myopathies comprehense a group of heterogenous diseases including polymyositis (PM), dermatomyositis (DM) and inclusion body myositis (IBM). The most common disease in persons $>50$ years is IBM. The prevalence of IBM in this particular age-group is $39.5 /$ million. The incidence of $\mathrm{PM} / \mathrm{DM}$ is $2-10 /$ million, and the prevalence $11 / 100,000$. Other organ manifestations could be present in IIM, specially in PM and DM. One example is interstitial lung disease which often lead to increased morbidity and mortality. In particular DM has an increased risk of cancer, probably also PM, but not IBM. In recent years identification of new clinical phenotypes of PM/DM has been made, mostly by myositisspecific antibodies. Some of these can be used as markers of prognosis and disease activity. For future epidemiological and clinical studies, which can increase our knowledge of these diseases, a unified, international classification that also include myositis-specific antibodies is highly warranted.

Idiopatiske inflammatoriske myopatier (IIM) kan defineres som kroniske immunmedierte muskelsykdommer av ukjent etiologi. Sykdommene i denne diagnosegruppen karakteriseres av cellulær infiltrasjon og/eller muskelcellenekrose i tverrstripet muskulatur. Tradisjonell klinisk klassifikasjon av disse er som følger:

- Polymyositt (PM)

- Dermatomyositt (DM)

- Myositt ved kollagenosesykdom

- Juvenil dermato/poly/myositt (JDM/JPM)

- Inklusjonslegememyositt (IBM)

- Øvrige (inklusive myositt assosiert med kreftsykdom)

En har i denne presentasjon valgt å begrense omtalen til polymyositt, dermatomyositt, og inklusjonslegememyositt.

\section{POLYMYOSITT/DERMATOMYOSITT}

\section{Arsaksforhold}

Det er trolig at både arv og miljø har betydning for sykdomsutvikling. Genetisk assosiasjon for poly- og dermatomyositt er i kaukasiske populasjoner koblet til HLA DRB1*0301 og DQA1*0501 (1). Ulike virusinfeksjoner er blitt foreslått som årsak til PM/DM men sikker sammenheng er ikke påvist (2). Videre er det usikkert om UV-stråling kan ha betydning for utvikling av dermatomyositt (3). Man kjenner i dag ikke til noen spesifikk miljøfaktor som direkte årsak til PM eller DM.

\section{Kliniske forhold}

Polymyositt ble klinisk først beskrevet av Wagner i 1886 (4). I 1891 ble dermatomyositt beskrevet av Unverricht (5) og i 1916 kom den første beskrivelsen av malignitetsassosiert dermatomyositt (6). De typiske kliniske manifestasjoner er progredierende proksimal muskelsvakhet, redusert muskelutholdenhet, artritt/artralgi, øsofagusdysmotilitet, interstitiell lungesykdom (ILD), hudsymptomer (Gottrons tegn/papler, heliotropt eksantem, subkutan kalsinose), kardiomyopati og antisyntetase-syndrom (ILD, artritt, feber, Raynaud og "mechanical hands").

Av disse er ILD den manifestasjon som er mest avgjørende for prognose og mortalitet. ILD sees hos omkring 1/3 (5-46\%) av pasientene (7).

DM forekommer også uten samtidlig muskelaffeksjon (amyopatisk DM), eller bare med subklinisk myositt (hypomyopatisk DM). 


\section{Diagnostikk}

Foruten kliniske symptomer baseres diagnostikken på MR-undersøkelse av muskulatur, muskelbiopsi, EMGundersøkelse og CK-verdi. Bohan og Peter $(8,9)$ foreslo i 1975 diagnostiske kriterier for poly- og dermatomyositt (Tabell 1). Disse er i dag fremdeles de mest brukte kriterier for diagnosen PM/DM.

I begynnelsen av 1980-tallet ble det myosittspesifikke antistoffet JO-1 påvist (10). Bohan og Peters kriterier omfatter naturlig nok ikke dette eller andre myosittspesifikke (MSA) eller myosittassosierte antistoffer (MAA). Det er derfor senere foreslått reviderte klassifikasjonskriterier for $\mathrm{PM} / \mathrm{DM}$ som inkluderer myosittspesifikke antistoffer. I tillegg kan inflammasjon påvist ved MR-undersøkelse av muskel erstatte kriterium 1 eller 2 (11) (Tabell 2).

Spesielt MSA-antistoffer kan definere mer homogene undergrupper av poly/dermatomyositt da de ulike antistoffene ofte kan assosieres med distinkte kliniske subgrupper. Dette er av stor betydning i forhold til nye epidemiologiske og kliniske studier.

\section{Myosittspesifikke antistoffer (MSA)}

Med MSA menes autoantistoffer som sees ofte ved IIM, og svært sjelden ved andre sykdommer eller hos friske personer. De deles gjerne inn i tre grupper som det fremgår av Tabell 3.

Det vanligste antisyntetase-antistoffet er anti-Jo1 som forekommer hos ca. 20\% (12) av pasienter med IIM. Antisyntetase-antistoff ansees som et obligat kriterium ved antisyntetase-syndrom. Ved dette syndromet er ofte muskelaffeksjonen lite uttalt, mens andre ekstramuskulære manifestasjoner kan dominere det kliniske bildet. Ofte er ILD den mest fremtredende manifestasjon. Om antisyntetase-antistoffene er av årsaksmessig betydning er ikke kjent, men der er påvist en positiv korrelasjon mellom titer av anti-Jo1 og sykdomsaktivitet (13).

Anti-SRP myositt er beskrevet hos ca. 4\% av pasienter med IIM (vanligst hos PM) (12). Det histologiske bilde er ofte en nekrotiserende myopati med lite uttalte inflammatoriske forandringer (14). Disse pasienter har som regel uttalt muskelsvakhet og forhøyde CK-verdier, samt dårlig behandlingseffekt av kortikosteroider. Anti MI-2 sees hos $4-14 \%$ av IIMpasienter, fortrinnsvis DM (15).

De myosittspesifikke antistoffene er således viktige kliniske hjelpemidler i forhold til diagnostikk, utredning, behandling og oppfølgning.

\section{Insidens og prevalens}

Årlig insidens av PM og DM estimeres til 2-10/million. I en svensk populasjonsbasert studie var insidensen 7,6/million (16). Insidensen har vært økende de senere år, men dette kan sannsynligvis forklares ved forbedret diagnostikk. Ahlstrom et al. påviste en prevalens av PM/DM på 11/100.000 (17).
Der er påvist en viss årstidsvariasjon av debut for PM og DM. Pasienter med antisyntetase-antistoff har $\varnothing \mathrm{kt}$ insidens i mars/april mens MSA-negative pasienter har økt insidens i juni/juli (18), noe som kan indikere at miljøfaktorer har innvirkning på sykdomsdebut.

\section{Demografi}

Gjennomsnittlig debutalder (hos voksne) er 40-50 år. Forholdet kvinner : menn er $2: 1$. Oddis et al. fant $\mathrm{i}$ en definert amerikansk befolkning en økt insidens av PM og DM hos mørkhudede i forhold til hvite (19). Andre rasemessige forskjeller er lite undersøkt.

Tabell 1. Diagnostiske kriterier for poly- og dermatomyositt (Bohan og Peter $(8,9))^{*}$.

1. Symmetrisk proksimal muskelsvakhet.

2. Forhøyde muskelenzymer i serum (CK, aldolase, ASAT, ALAT, LD).

3. EMG med polyfasiske MUP, "sharp waves" og repetitive utladninger.

4. Muskelbiopsi; Degenerasjon, regenerasjon, nekrose, fagocytose og interstitielle mononukleære infiltrater.

5. Typiske hudeksantem (eks heliotropt eksantem, Gottrons tegn/papler).

For å stille diagnosen DM må kriterium 5 være til stede.

Mulig PM/DM $=2$ kriterier

Trolig PM/DM $=3$ kriterier

Definitiv $\mathrm{PM} / \mathrm{DM}=4$ kriterier

* Kriteriene forutsetter at andre årsaker til myopati er ekskludert.

Tabell 2. Reviderte klassifikasjonskriterier for poly/dermatomyositt (Targoff et al. (11)).

1. Symmetrisk proksimal muskelsvakhet.

2. Forhøyde muskelenzymer.

3. EMG med myopatiske "MUP", positive "sharp waves", repetitive utladninger.

4. Muskelbiopsi; degenerasjon, regenerasjon, nekrose, fagocytose og interstitielle mononukleære infiltrater.

5. En av de myosittspesifikke antistoffene.

6. Typiske hudeksantem.

Positiv MR-undersøkelse med henblikk på inflammasjon kan erstatte kriterium 1 eller 2. For å stille diagnosen DM må kriterium 6 være til stede.

Mulig $\mathrm{PM} / \mathrm{DM}=2$ kriterier

Trolig PM/DM $=3$ kriterier

Definitiv $\mathrm{PM} / \mathrm{DM}=4$ kriterier

Tabell 3. Myositt-spesifikke antistoff (MSA).

1. Anti-syntetase antistoff (eks. anti JO-1, PL-7, PL-12, EJ, OJ)

2. Anti-SRP antistoff (Signal Recognition Particle)

3. Anti-MI2 antistoff 


\section{Mortalitet}

Der er varierende resultater i de ulike studier av mortalitet ved PM/DM. Sigurgeirsson et al. (20) fant en 5års overlevelse på $65 \%$ ved $\mathrm{PM}$ og $60 \%$ ved DM. 10 års overlevelse var henholdsvis 52\% og 50\%. I en finsk retrospektiv studie var 5-års overlevelse $75 \%$ for PM og 63\% for DM. 10-års overlevelse var 55\% og $53 \%$ (21). I denne studien hadde DM pasienter 1,5 ganger høyere dødelighet enn PM, justert for alder og kjønn. Den vanligste dødsårsaken ved PM og DM samlet var hjerte/karsykdom, henholdsvis $37 \%$ og $31 \%$.

\section{Cancerrisiko}

Det er kjent at spesielt DM-pasienter har en økt risiko for cancersykdom. I den finske studien referert ovenfor var cancer dødsårsak hos 33\% av DM-pasienter, mot 9\% ved PM (21).

I en svensk populasjonsbasert kohortstudie med 788 PM- og DM-pasienter ble det påvist en økt relativ risiko for cancersykdom. Mannlige PM-pasienter hadde en økt relativ risiko på 1,8, kvinner 1,7. Hos DMpasienter var relativ risiko 2,4 hos menn, og 3,4 hos kvinner (20).

En skandinavisk retrospektiv studie med 618 DMpasienter påviste en sterk assosiasjon til malign sykdom. 198 pasienter hadde cancer som ga en SIR (standard incidence ratio) på 3,0. 115 av 198 utviklet cancer etter dermatomyositt-diagnose. I denne studien var spesielt cancer i ovarie, lunge, pancreas, ventrikkel og tykktarm samt non-Hodgkin lymfom overrepresentert. 137 av 914 PM-pasienter hadde cancer (SIR 1,3), hvorav 95 ble diagnostisert etter polymyositt-diagnose. Hos disse var det spesielt økt insidens av non-Hodgkin lymfom, lunge og blærecancer. Majoriteten av kreftsykdommene ble diagnostisert innen 1 år etter myosittdiagnose (22).

Det myosittassosierte antistoffet p-155 (i form av anti 155/140-antistoff) ble i en studie påvist hos 18,4\% av myosittpasienter, og da bare hos DM-pasienter. $50 \%$ av disse hadde cancer-assosiert myositt (23). 97\% av pasientene som ikke hadde dette antistoff hadde heller ikke cancer-assosiert myositt (dvs. negativ prediktiv verdi 97\%). Dette antistoff kan derfor muligens brukes til å identifisere de myosittpasienter som har en økt risiko for cancerutvikling.

\section{Prognostiske faktorer}

Høy alder ved debut er en prognostisk faktor for mortalitet hos PM/DM-pasienter (21). Andre prediktorer for dårlig prognose er diagnoseforsinkelse, tidspunkt for oppstart av behandling, mannlig kjønn, dysfagi, hjerte/lunge affeksjon, positiv anti-SRP og antisyntetase-antistoff $(21,24)$.

Ved revmatologisk avdeling, Rikshospitalet, er der utført en retrospektiv studie (1985-2006) med 30 antisyntetasesyndrom pasienter. 4 pasienter døde under observasjonstiden, og overlevelse 10 år etter diagnose var 50\%. 30\% utviklet "end-stage" lungeaffeksjon under observasjonsperioden (25). Studien viser en betydelig økt morbiditet og mortalitet for pasienter med anti-syntetasesyndrom.

\section{Prognose}

I en retrospektiv nederlandsk studie (24) fant man at sykdomsforløpet ved PM og DM kunne deles inn i tre grupper; Monocyklisk i 20\% (dvs. i remisjon 24 måneder fra diagnosetidspunkt), polycyklisk i 20\% (dvs. oppbluss av sykdomsaktivitet etter remisjon) og kronisk kontinuerende i 60\% (dvs. persisterende sykdom 24 måneder etter diagnose). I denne studien var det ingen sikker sammenheng mellom sykdomsforløp og alder, kjønn, myositt-type eller myositt-spesifikke antistoff. Studien viser at majoriteten av pasientene etter 2 år ikke var i remisjon, til tross for behandling.

\section{INKLUSJONSLEGEMEMYOSITT (IBM)}

De histologiske forandringer ved IBM ble første gang beskrevet av Chou i 1967 (26). Carpenter et al. definerte i 1978 sykdommen som en undergruppe til IIM (27), og i 1991 påviste man amyloid i muskelfibrene (28).

IBM kan inndeles i 3 undergrupper; sporadisk form, familiær form og hereditær form (sistnevnte med debut i 20-30 års alder, sjelden affeksjon av quadriceps og histologisk uten inflammatoriske infiltrater). En vil her kun omtale den sporadiske formen av IBM.

\section{Arsaksforhold}

Inklusjonslegememyositt har en meget sterk assosiasjon til HLA-DR3 og 8.1 MHC haplotype og er en av de mest "robuste" HLA-sykdomsammenhenger som er registrert (29). Det er ukjent hva som forårsaker sykdommen, men flere tilfeller av samtidig opptreden av IBM og systemiske bindevevssykdommer og infeksjoner (HIV, Hepatitt C) er beskrevet (29).

\section{Kliniske forhold}

IBM skiller seg klinisk fra poly- og dermatomyositt da den er mer asymmetrisk i utbredelse, mer langsomt progredierende, og affiserer også distal muskulatur, evt. ansiktsmuskulatur. En vanlig ekstramuskulær manifestasjon er øsophagusaffeksjon (opptil 2/3), men ikke hjerte/lungeaffeksjon. Myosittspesifikke antistoffer påvises svært sjelden og CK-verdier er kun moderat forhøyet. Der er ikke påvist økt risiko for cancer ved IBM. IBM svarer dårlig på immunsuppressiv behandling, og til tross for langsom progresjon kan den over tid gi alvorlig redusert muskulær funksjon sammenlignet med PM/DM.

\section{Diagnostikk}

Griggs et al. (30) foreslo diagnostiske kriterier for IBM i 1995 (Tabell 4).

Trolig IBM har funn som i A og B, men oppfyller ikke alle kriterier i muskelbiopsien. Mulig IBM oppfyller ikke alle funn i A eller B, heller ikke alle kriterier i muskelbiopsien som er påkrevet for diagnose. 
Tabell 4. Foreslåtte diagnostiske kriterier for IBM.

\section{Karakteristika}

A. Kliniske funn

1. Sykdomsvarighet $>6$ måneder.

2. Aldersdebut $>30$ år.

3. Langsomt progredierende muskelsvakhet/atrofi; selektivt mønster med tidlig affeksjon av quadriceps og fingerfleksorer, evt. asymmetrisk.

4. Dysfagi.

B. Laboratoriefunn

1. CK-verdier $<12$ x normalverdi.

2. EMG; Myopatisk eller blandet mønster med både korte og lange "MUP" og spontan aktivitet.

C. Muskelbiopsi

1. Nekrose og regenerasjon av muskelfibre.

2. Mononukleær cellinfiltrat $i$ endomysiet.

3. Mononukleær cellinvasjon av ikke-nekrotiske fibre (spes CD8+ Tceller)

4. Oppgradering av MHC klasse I.

5. Rimmed vacuoles.

6. Amyloid i muskelfiber.

7. Ved elektronmikroskopi; Nukleære og/eller cytoplasmatiske inklusjoner.

8. COX-negative fibre.

\section{Hereditet}

\section{Assosierte sykdommer}

IBM kan assosieres med

1. Andre autoimmune sykdommer, kollagenoser.

2. Infeksjoner (eksempelvis HIV, Hepatitt C).

\section{Diagnostiske kriterier for IBM}

Definitiv IBM krever muskelbiopsi med følgende funn:

1. Invasjon av mononukleære celler i ikke-nekrotiske fibre.

2. Vakuoler i muskelfibre.

3. Intracellulær amyloidavleiringer eller

4. 15-18 nm tubulære filament.

Hvis disse biopsifunn er til stede er hverken laboratoriefunn eller klinikk obligate for diagnose.

\section{Insidens og prevalens}

Insidens av IBM varierer mellom forskjellige etniske grupper. Det er lavere insidens i Korea, Midt-Østen og ved Middelhavet. Insidensen er i midlertid vanskelig å estimere bl.a. på grunn av sykdommens snikende debut. I en nederlandsk kohortstudie var gjennomsnittlig symptomvarighet før diagnose 10 år for menn og 14 år for kvinner (31).

Prevalensen er beregnet til 4,9-10,7/million. Prevalensen øker med stigende alder slik at det i aldersgruppen > 50 år er påvist en prevalens på 39,5/million (29).

\section{Demografi}

Kjønnsfordeling ved IBM er motsatt den for PM og $\mathrm{DM}$ da menn affiseres dobbelt så hyppig som kvinner. Inklusjonslegememyositt er den vanligste forekommende IIM-sykdom i aldersgruppen > 50 år. I den nederlandske studien med 64 pasienter (43 menn, 21 kvinner) var middelalder ved symptomdebut 57 respektive 59 år. 13 av 64 pasienter var under 50 år ved debut (31).

\section{Mortalitet}

Der er ikke noen utført studier av mortalitet eller dødsårsaker ved inklusjonslegememyositt.

\section{Prognose}

Det foreligger få studier av prognose ved IBM. I samme studie som nevnt ovenfor gikk det i gjennomsnitt 13 år fra symptomdebut til at pasienten brukte rullestol. Ingen av de 64 pasientene sluttet å jobbe før normal pensjonsalder (31). Til tross for at IBM har mindre uttalte ekstramuskulære manifestasjoner (unntatt dysfagi) kan den på sikt gi betydelig grad av fysisk invaliditet og redusert livskvalitet.

\section{FORKORTELSER}

IIM = idiopatiske inflammatoriske myopatier

$\mathrm{PM}=$ polymyositt

$\mathrm{DM}=$ dermatomyositt

IBM = inklusjonslegememyositt

$\mathrm{JDM}=$ juvenil dermatomyositt

$\mathrm{JPM}=$ juvenil polymyositt

ILD = interstitiell lungesykdom

MSA = myositt-spesifikke antistoff

MAA $=$ myositt-assosierte antistoff

$\mathrm{SIR}=$ standard incidence ratio

\section{REFERANSER}

1. O'Hanlon TP, Carrick DM, Targoff IN et al. Immunogenetic risk and protective factors for the idiopathic inflammatory myopathies: Distinct HLA-A, -B, -Cw, -DRB1, and -DQA1 allelic profiles distinguish European American patients with different myositis autoantibodies. Medicine 2006; 85: 111-127.

2. Dorph C, Lundberg EI. Idiopathic inflammatory myopathies-myositis. Best Pract Res Clin Rheumatol 2002; 16: $817-832$.

3. Hengstman GJ, Venrooij WJ, Vencovsky J et al. The relative prevalence of dermatomyositis and polymyositis in Europe exhibits a latitudinal gradient. Ann Rheum Dis 2000, 59: 141-142.

4. Wagner E. Ein fall von akuter polymyositis. Deutsch Arch Klin Med 1886; 40: 241-266. 
5. Unverricht H. Dermatomyositis acuta. Deutsch Med Wochenschr 1891; 17: 41-44.

6. Kankeleit H. Uber primare nichteitrige polymyositis. Deutsch Arch Klin Med 1916; 120: 335-348.

7. Fathi M, Lundberg EI. Interstitial lung disease in polymyositis and dermatomyositis. Curr Opin Rheumatol 2005; 17: 701-706.

8. Bohan A, Peter JB. Polymyositis and dermatomyositis (first of two parts) N Engl J Med 1975; 292: 344-347.

9. Bohan A, Peter JB. Polymyositis and dermatomyositis (second of two parts) N Engl J Med 1975; 292: 403407.

10. Mathews BM, Bernstein MR. Myositis autoantibody inhibits histidyl-tRNA synthetase: a model for autoimmunity. Nature 1983; 304: 177-179.

11. Targoff IN, Miller FW, Medsger TA Jr et al. Classification criteria for the idiopathic inflammatory myopathies. Curr Opin Rheumatol 1997; 9: 527-535.

12. Hengstman GJ, Brouwer R, Egberts WT, Seelig HP, Jongen PJ, van Venrooij WJ, van Engelen BG. Clinical and serological characteristics of 125 Dutch myositis patients. Myositis specific autoantibodies aid in differential diagnosis of the idiopathic inflammatory myopathies. J Neurol 2002; 249: 69-75.

13. Stone KB, Oddis CV, Fertig N et al. Anti-Jo1-antibody levels correlate with disease activity in idiopathic inflammatory myopathy. Arthritis Rheum 2007; 56: 3125-3131.

14. Hengstman GJD, ter Laak HJ, Vree Egberts WTM et al. Anti-signal recognition particle autoantibodies: Marker of a necrotising myopathy. Ann Rheum Dis 2006; 65: 1635-1638.

15. Hengstman GJD, van Engelen BGM, Vree Egberts WT, van Venrooij WJ. Myositis-spesific autoantibodies: overview and recent developments. Curr Opin Rheumatol 2001; 13: 476-482.

16. Weitoft T. Occurence of polymyositis in the county of Gavleborg, Sweden. Scand J Rheumatol 1997; 26: 104-106.

17. Ahlstrom G, Gunnarsson LG, Leissner P et al. Epidemiology of Neuromuscular diseases, including the postpolio sequelae, in a Swedish county. Neuroepidemiology 1993; 12: 262-269.

18. Sarkar K, Weinberg CR, Oddis CV et al. Seasonal influence on the onset of idiopathic inflammatory myopathies in serologically defined groups. Arthritis Rheum 2005; 52: 2433-2438.

19. Oddis CV, Conte CG, Steen VD et al. Incidence of polymyositis-dermatomyositis: a 20-year study of hospital diagnosed cases in Allegheny County, PA 1963-1982. J Rheumatol 1990; 17: 1329-1334.

20. Sigurgeirsson B, Lindelof B, Edhag O, Allander E. Risk of cancer in patients with dermatomyositis or polymyositis. A population-based study. N Engl J Med 1992; 326: 363-367.

21. Airio A, Kautiainen H, Hakala M. Prognosis and mortality of polymyositis and dermatomyositis patients. Clin Rheumatol 2006; 25: 234-239.

22. Hill CL, Zhang Y, Sigurgeirsson B et al. Frequency of specific cancer types in dermatomyositis and polymyositis: A population-based study. Lancet 2001; 357: 96-100.

23. Chinoy H, Fertig N, Oddis VC, Ollier ERW, Cooper GR. The diagnostic utility of myositis autoantibodytesting for predicting the risk of cancer-associated myositis. Ann Rheum Dis 2007; 66: 1345-1349.

24. Bronner IM, van der Meulen MFG, de Visser M et al. Long-term outcome in polymyositis and dermatomyositis. Ann Rheum Dis 2006; 65: 1456-1461.

25. Gran JT, Andersson H, Norby GE, Midtvedt Ø, Gunnarsson R, Palm Ø, Gilboe IM. Antisynthetase syndrome; A clinical and serological study of Norwegian patients. Ann Rheum Dis 2007; 66 (Suppl II): 209.

26. Chou SM. Myxovirus like structures in a case of human chronic polymyositis. Science $1967 ; 158$ : $1453-1455$.

27. Carpenter S, Karpati G, Heller I, Eisen A. Inclusion body myositis: a distinct variety of idiopathic inflammatory myopathy. Neurology 1978; 28: 8-17.

28. Mendell JR, Sahenk Z, Gales T, Paul L. Amyloid filaments in inclusion body myositis: novel findings provide insight into nature of filaments. Arch Neurol 1991; 48: 1229-1234.

29. Needham M, Mastaglia LF. Inclusion body myositis: Current pathogenetic concepts and diagnostic and therapeutic approaches. Lancet Neurol 2007; 6: 620-631.

30. Griggs RC, Askanas V, Di Mauro S et al. Inclusion body myositis and myopathies. Ann Neurol 1995; 38: 705-713.

31. Badrising UA, Maat-Schieman MLC, van Houwelingen JC et al. Inclusion body myositis. Clinical features and clinical course of the disease in 64 patients. J Neurol 2005; 252: 1448-1454. 